\title{
Consumers' Overconfidence Biases in Relation to Social Exclusion
}

\author{
Woong-Hee HAN ${ }^{1}$
}

Received: March 20, 2020 Revised: May 24, 2020 Accepted: June 10, 2020

\begin{abstract}
Unlike previous studies of overconfidence bias that have been looking for causes of overconfidence bias in human cognitive error or in the desire to view oneself positively, this study presents the cognitive narrowing resulting from the social exclusion experience as the condition of overconfidence bias and investigates the mechanism of cognitive narrowing to overcome the negative emotions from social exclusion, and how overconfidence bias occur due to cognitive narrowing. Current study was performed with 94 undergraduate students. Participants were randomly assigned to social exclusion experience group or non-experience group. We analyzed how the degree of bias of overconfidence differs according to the social exclusion experience. The degree of overconfidence bias of the social exclusion experience group was higher than that of the non-experience group, and the difference was statistically significant. This study extends the concepts of escaping theory and cognitive narrowing to human cognitive bias and confirmed that social exclusion experience increased cognitive narrowing and overconfidence bias. Implications of this research and future research directions were discussed.
\end{abstract}

Keywords : Overconfidence Bias, Social Exclusion

JEL Classification Code: D11, M31

\section{Introduction}

People claim to be better than others on a variety of traits and attributes, including honesty (Brown, 2012), leadership skills (Dunning, Heath, \& Suls, 2004), popularity (Zuckerman \& Jost, 2001), and safe driving (Svenson, 1981). Business people claim that their firms are better than the average firm (Cooper, Woo, \& Dunkelberg, 1988), engineers report that their work is superior to their peers' work (Zenger, 1992), and venture capitalists are overconfident in their

\footnotetext{
${ }^{1}$ First Author and Corresponding Author. Associate Professor, Department of Business Administration, Myongji University, Korea. Email: whhan@mju.ac.kr

(c) Copyright: The Author(s)

This is an Open Access article distributed under the terms of the Creative Commons Attribution Non-Commercial License (http://Creativecommons.org/licenses/by-nc/4.0/) which permits unrestricted noncommercial use, distribution, and reproduction in any medium, permits unrestricted noncommercial use,
provided the original work is properly cited.
}

ability to predict which entrepreneurs will succeed (Zacharakis \& Shepherd, 2001). Consumers also tend to have overconfidence in their decision-making in the purchasing process.

Social cooperation and support is required for people to survive. For survival, people need to belong to groups and adapt their ideas and behaviors to the norm of the group. If a person is rejected or excluded from the group, the person will be stressed and cognition of the person may be impaired. Previous studies of overconfidence bias are looking for causes of over-confident bias in human cognitive error (Gigerenzer, 2008; Kahneman \& Tversky, 1996) or in the desire to view oneself positively (Dunning, 2005; Fabricius \& Buttgen, 2013). Unlike previous studies, present study starts with the recognition that human cognitive errors are not congenital or constant. And this study presents the cognitive narrowing resulting 
from the social exclusion experience as such conditions and situations.

This research focuses on cognitive narrowing to explain how social exclusion experience causes cognitive impairment and examines how cognitive narrowing influences on consumer's judgment and reasoning and leads to overconfidence bias. This research is anticipated to contribute to the research of social exclusion and the resulting overconfidence bias of consumers and the marketing tactics.

\section{Literature Review}

Overconfidence occurs when people's confidence in our judgments, inferences, and predictions is much higher than actual accuracy. Many studies in marketing and psychology have shown that people tend to be overconfident that their knowledge is accurate (Alba \& Hutchinson, 2000). The different meanings of the term overconfidence all reflect different ways of comparing subjective beliefs and reality. Among them, two methods have been used, probabilistic prediction of the accuracy of statements and choices, and prediction of confidence intervals. In the first method, overconfidence occurs when the average confidence judgment exceeds the overall proportion of the exact statement or choice. In the second method, overconfidence occurs when the confidence interval around the estimate is very narrow (Hoffrage, 2004).

Kahneman and Tversky (1996) viewed overconfidence as a cognitive bias caused by errors in processing information. These cognitive theories do a good job accounting for important features of the empirical evidence, such as the finding that people underestimate their performance on easy tasks and show underplacement when considering difficult tasks (Moore \& Small, 2007) or the finding that people see themselves as worse than average on rare traits and behaviors (Kruger \& Burrus, 2004).

Some research argues that the irrational aspect of consumers aroused by the inherent limitations of human cognitive capability (Kahneman \& Tversky, 1982). Other research argues that the irrationality has its own rationality (Gigerenzer, 2008). The former view argues that rational judgments and decision-making are biased due to cognitive limitations. Dual process model explains why people fall into cognitive error. According to this model, if System 1 is activated, people can fall into cognitive error. This model is the basis on which System 1 can operate according to the nature of the processed task and the motivation of the people (Logg, Haran, \& Moore, 2018).

In an early study of probabilistic prediction methods, Adams and Adams (1961) conducted an experiment that asked participants to tell the subjective probabilities (from $0 \%$ to $100 \%$ ) of various events. In this experiment, the confidence value was determined by the difference between the answers of the respondents with $\mathrm{x} \%$ confidence and the actual correct answer. Subsequent studies use twoalternative forced-choice tasks (2AFC) to allow participants to choose which of two alternatives is correct. For example, "Which city is located farther north, Rome or New York?" or "Is Absinthe a gem or a drink?" are asked to the participants. Participants choose one of the two and then immediately answer with a $10 \%$ interval from $50 \%$ to $100 \%$ as to whether they have chosen the correct answer.

Since keeping up a steady social relationship is so significant for human endurance and security, the longing to have a place is one of the most essential and key inspirations (Smith, Murphy, and Coats 1999). Along these lines, considers have indicated that what is acknowledged and dismissed by social gatherings has a wide scope of consequences for people. Wellbeing, joy and prosperity are firmly identified with whether individuals are acknowledged or denied, and the individuals who are denied of close social relationships have more negative mental or physical outcomes than those with solid interpersonal organizations (Cacioppo, Hawkley, and Berntson, 2003). Social rejection can likewise cause physiological reactions, for example, raised pulse, torment related mind zones being enacted (Eisenberger, Lieberman, and Williams, 2003), and negative consequences for mental prosperity.

Exclusion from social gatherings has been appeared to impede intellectual capacity. The individuals who experience social rejection have been appeared to twist time observation, to underline the present as opposed to the future, to show dormant inactivity, and to maintain a strategic distance from mindfulness (Twenge, Catanese, and Baumeister, 2003). Exclusion from social gatherings can prompt tension or different types of passionate misery that can prompt transient hindrances of psychological capacity, bringing about different intellectual deficiencies, for example, sensible thinking issue (Baumeister, Twenge, and Nuss, 2002).

At the point when individuals find the chance of social prohibition, they might have the option to smother their passionate reactions, which will seize human selfadministrative frameworks. On the off chance that the assets of oneself are completely used to smother feelings, they won't be sufficient to control the subjective procedure. Subsequently, progressively programmed intellectual procedures can be worked generally unblemished, yet controlled procedures can be hard to work. At the end of the day, social rejection corners a portion of the assets of the self-execution work, specifically sabotaging the controlled procedure. Inevitably, they will have less effect on generally programmed (less proficient and less controlled) 
assignments, yet harm can be found in errands that require dynamic speculation, for example, thinking and rationale (Han, 2020a).

The Escape Model depends on the hypothesis of contrasting the perfect self and the genuine self and has been applied to account for reckless practices, for example, voraciously consuming food and self-destruction (Heatherton and Baumeister, 1991). Mindfulness can here and there be oppressive for individuals, particularly when their gauges are high or when they are described by hairsplitting and when they neglect to meet their objectives or goals (Duval and Wicklund, 1972).

One approach to lessen negative feelings is to decrease mindfulness, making the inconsistency among self and related measures not, at this point articulated (Duval and Wicklund, 1972). This decrease of mindfulness, cognitive narrowing, is one of the significant kinds of getaways considered in escape models.

On account of cognitive narrowing, the focal point of consideration is limited by concentrating just on current thoughts within reach, explicit and low-level thoughts, and declining to think extensively and genuinely (Baumeister, 1990). The more individuals attempt to stay away from important reasoning, the more outlandish they are to be judicious and less basic, and the almost certain they are not to discover any questions of convictions or ends.

The explanation behind nonsensical reasoning or unreasonable discernment is that the ordinary example of thinking was interfered, bringing about a sort of mental void (Bauer and Anderson, 1989; Butterfield and Leclair, 1988).

Cognitive narrowing likewise keeps us from considering the drawn-out significance of specific practices, for instance, causal reasoning (Faver, 2004). Among the different subjective bends brought about by cognitive narrowing, the bogus attribution and the absence of causal reasoning are especially unmistakable, which is identified with the overconfidence error (Han, 2020a).

Negative emotions resulting from experiences of social exclusion can be expected to lead to cognitive narrowing. Cognitive narrowing can also be expected to cause cognitive distortions and cognitive errors. Specifically, the group who experienced social exclusion can be expected to have higher cognitive error, especially overconfidence bias, than the group who did not experience social exclusion. Social exclusion dominates the resources of the self-execution function, undermining the controlled process. Consequently, they will have less influence on automatic tasks, and damage is found in tasks that require active reasoning and logic. Based on these studies, the hypothesis can be drawn as follows.

Hypothesis: People with social exclusion experience will have a higher degree of overconfidence bias than people without social exclusion experience.

\section{Research Methods}

This investigation was directed with 94 understudies in Seoul. Members were randomly appointed to the gathering who experienced social prohibition and the gathering who didn't encounter social avoidance. We broke down how the level of overconfidence bias varies as indicated by the experience of social exclusion.

The control of social exclusion encounters has used situation control strategies for applying for enrollment (Wan, $\mathrm{Xu}$, and Ding, 2014). Subjects were given a scenario and requested to read it carefully and identify the character's job and feelings. The scenario shows that the primary character getting ready for work is anxious to join SUCCESS, an occupation planning club that gives strong data and powerful learning techniques and flaunts high business achievement rates. It contains that the fundamental character has presented a participation application to the activity planning club ' SUCCESS '. Under social rejection, the principle character was reached by the club a couple of days after the fact that his application was denied. What's more, under social consideration, the principle character was educated that the application was endorsed.

Next, members were asked to react to control check inquiry about sentiments of prohibition or disregard while depicting the experience ( $1=$ strongly disagree, $7=$ strongly agree). The members were then given an undertaking identified with overconfidence and requested to determine.

The following five questions were asked to participants in the experiment to measure overconfidence bias. "Which of Argentina's 'Buenos Aires' or Turkey's 'Encara' are more populated as of 2015?", "Which company ranks higher among McDonald's and Intel in the 2012 Fortune Global Business List?", "Which country has the longer average life expectancy in Australia and Denmark as of 2015?", "As of 2009, which district has the highest population density between Seodaemun-gu and Yeongdeungpo-gu?", "Which snack has a higher calorie content per 100 grams, Choco Heim or Kkokolkon?" Participants were asked to answer one question and then mark the additional question, "How confident are you that your answer to that question is correct?" in the numbers given at intervals of $50 \%$ to $100 \%$. The degree of overconfidence was measured by subtracting the percentage of correct answers (=number of correct questions/5) from the average of the confidence values that participants indicated they were confident of their answers. If this participant answered two of the five questions correctly, the percentage of correct answers would be $40 \%(=2 / 5)$, and overconfidence would be $30 \%$ $(=70 \%-40 \%)$. 


\section{Research Results}

Subjects' responses to the control check question for social rejection were calculated to obtain a manipulation check score (Wan, Xu, \& Ding, 2014). Participants under rejected condition (vs. accepted) showed more exclusion feeling as intended $(\mathrm{M}=4.90$ vs. $\mathrm{M}=2.42, t(92)=-13.134, \mathrm{p}<.001)$ and this confirm that the manipulation of social exclusion worked well.

As shown in $<$ Table $1>$ and $<$ Figure $1>$, there was not significant difference in the percentage of correct answers between two groups $\left(M_{\text {ex }}=30.95\right.$ vs. $M_{\text {in }}=29.23, t(92)=-$ $.403, \mathrm{p}>.1)$. On the other hand, the confidence value was significantly different between two groups $\left(\mathrm{M}_{\mathrm{ex}}=75.33\right.$ vs. $\left.\mathrm{M}_{\text {in }}=65.31, t(92)=-4.215, \mathrm{p}<.00\right)$. Finally, the degree of overconfidence bias of the socially excluded group was higher than that of the socially non-excluded group, and the difference was statistically significant $\left(\mathrm{M}_{\mathrm{ex}}=44.38\right.$ vs. $\mathrm{M}$ in $=36.08, t(92)=-2.068, \mathrm{p}<.05)$. These results support the hypothesis.

Table 1: Social Exclusion and Overconfidence

\begin{tabular}{|l|l|c|c|c|c|}
\hline & & N & Mean & SD & $\begin{array}{c}\text { Standard } \\
\text { Error of } \\
\text { the Mean }\end{array}$ \\
\hline $\begin{array}{l}\text { Over } \\
\text { confidence }\end{array}$ & Exclusion & 52 & 44.38 & 21.44 & 2.97 \\
\cline { 2 - 6 } & Inclusion & 42 & 36.08 & 16.38 & 2.52 \\
\hline
\end{tabular}

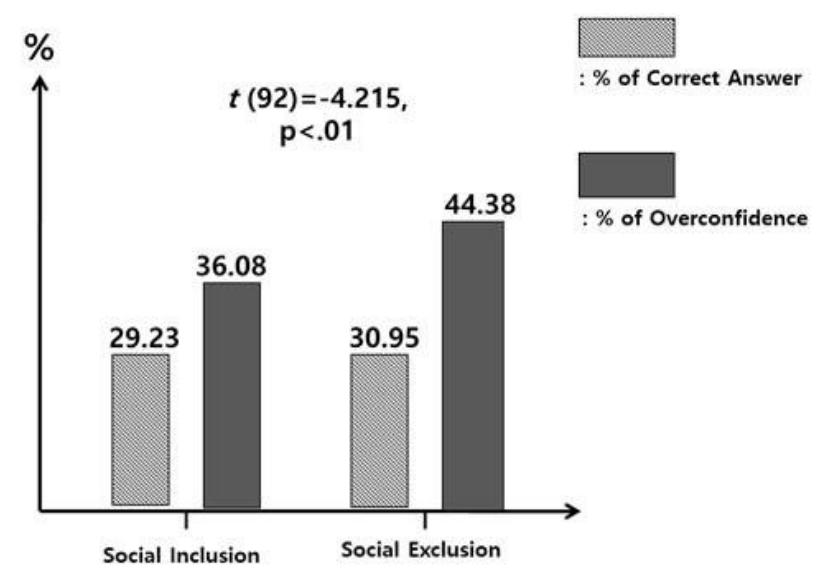

Figure 1: Social Exclusion and Overconfidence

\section{Conclusions}

This research observed that the occurrence of overconfidence bias in the people that accomplished social exclusion was higher than that in the people that didn't encounter social rejection. A dual-process model of thinking explains many errors in people's rational thinking process by assuming two different human reasoning systems (Kahneman \& Frederick, 2002; Stanovich \& West, 2000). A dual-process model has a variety of aspects, but generally the System 1 (or heuristic system) tends to solve problems based on prior knowledge or beliefs, while the System 2 (or analytical system) allows inferences based on logical criteria. If there is not enough time, lack of motivation, or lack of cognitive resources for cognitive activities, the operation of System 1's can easily and quickly lead to human thinking. It can also be expected that System 1 will operate in the case of cognitive narrowing in which the cognitive scope of operation is consciously and unconsciously reduced, and that various cognitive errors will occur.

In this examination, it was normal that intellectual mistake will happen when System 1 works when cognitive narrowing happens to conquer consumers' social avoidance encounters and negative feelings. As it were, this examination centered around the experience of prohibition or dismissal of shoppers just as the intellectual reaction procedure as a condition under which System 1 works. Past examinations have concentrated uniquely on the mechanism that the negative emotions of buyers can cause cognitive narrowing, and this intellectual narrowing realizes different psychological mistakes or subjective twists. This examination was planned to foresee and distinguish the component by which mistakes or inclination would be in the activity of System 1. As appeared in the results of this investigation, if the social prohibition experience causes cognitive narrowing and this causes psychological mistakes through the activity of System 1, the event of different cognitive biases notwithstanding the mistakes of inferencing thinking, social rejection and subjective inclinations. It is by all accounts clarified by cognitive narrowing.

Unlike previous studies of overconfidence bias that are looking for causes of overconfidence bias in human cognitive error or in the desire to view oneself positively (Dunning, 2005; Fabricius \& Buttgen, 2013; Gigerenzer, 2008; Kahneman \& Tversky, 1996), this study presents the cognitive narrowing resulting from the social exclusion experience as the condition of overconfidence bias.

This investigation has the following theoretical implications. First, it expands the idea of ambiguous selfawareness, escape model and cognitive rigidity to analyze addiction such as compulsive and impulsive consumption (Han, 2020b, 2020c, 2020d) to cognitive error. Second, it identified the mechanism of social exclusion by cognitive narrowing theory and dual process theory.

Therefore, current study theoretically contributes by extending the concepts of evasive self-awareness, 
cognitive narrowing, and escape theory which are used to explain addiction behavior such as compulsive buying to consumer's cognitive bias. Additionally, this research verified the mechanisms of the social exclusion, cognitive narrowing, and dual process models. Therefore, it is meaningful that the previous studies (Han, 2020a) on the phenomenon of irrational thinking caused by cognitive narrowing were expanded to a new phenomenon like overconfidence biases, and the principle of occurrence was clarified.

In practice, current research suggests that it is required to anticipate the results of consumers' purchasing decisions and behaviors and to establish appropriate marketing communication strategies in consideration of the characteristics of target consumers. In other words, it is required to understand the social exclusion experience, the weakness in self-awareness, and the cognitive narrowing strategy as a countermeasure of target consumers. And marketers need to decide on marketing communication strategy by considering characteristics such as overconfidence bias that can appear in consumers' decisionmaking process and information processing process. For example, consumers with cognitive narrowing tend to be overly confident in their judgments and decisions than those who do not, so consumers with these characteristics will likely have confidence in information processing itself, regardless of the accuracy of information processing. Therefore, the strategy of increasing the amount and level of information provided to these types of consumers or limiting the amount and level of information processing on the contrary, or conveying the information through an easy-toprocess media can be considered. In addition, consumers who show overconfidence bias due to cognitive narrowness are likely to show impulse buying and overconsumption by showing excessive optimism and unrealistic thinking about the future, so appropriate predictions and education will be needed in terms of consumer policy. Moreover, because there is a likelihood that the group with overconfidence bias may not easily switch brands, a strategy that leads them to loyal customers or a strategy that induces trials to seek variety will be appropriate.

Also, as in studies in which the type of heuristic affects mobile social commerce (Kim \& Yang, 2019), overconfidence biases are likely to be more likely to appear in mobile or online purchasing situations and marketers need to establish communication strategies that take into account consumer purchasing conditions.

Finally, a solid social resistance implies that an individual can control himself such that jelly himself and advances their own advantages over the long haul, remembering playing out a smooth cognitive movement for a positive passionate state.

Social inclusion is an important for the welfare of individuals and the entire society. According to a recent study of Black Friday consumption (Lee, Chun, \& Choi, 2019),
Korean consumers are more individualistic than American consumers. Therefore, diverse efforts are required to reduce social exclusion so as to maintain a sound consumer activities and healthy social community.

This investigation has limitations that the example was gathered uniquely from understudies, not customers of different ages and occupations, and didn't look at social prohibition and other estimation apparatuses for cognitive narrow. At long last, this examination just inspected the impacts of social avoidance and psychological narrowing on overconfidence bias, anyway future investigations need to study different kinds of cognitive mistakes.

\section{References}

Adams, J. K., \& Adams, P. A. (1961). Realism of confidence judgments, Psychological Review, 68(1), 33-45.

Alba, J. W., \& Hutchinson, J. W. (2000). Knowledge Calibration: What Consumers Know and What They Think They Know, Journal of Consumer Research, 27(2), 123-156.

Baumeister, R. F. (1990). Anxiety and deconstruction: On Escaping the Self, In J. M. Olson, \& M. P. Zanna (Eds.), Ontario Symposium on Personality and Social Psychology. Self-Inference Processes: The Ontario Symposium, 6(p. 259291). Lawrence Erlbaum Associate, Inc.

Baumeister, R. F., Twenge, J. M., \& Nuss, C. K. (2002). Effects of social exclusion on cognitive processes: Anticipated aloneness reduces intelligent thought, Journal of Personality and Social Psychology, 83, 817-827.

Bauer, B. G., \& Anderson, W. P. (1989). Bulimic beliefs: Food for thought, Journal of Counseling and Development, 67(7), 416-419.

Brown, J. D. (2012). Understanding the better than average effect: Motives (still) matter, Personality and Social Psychological Bulletin, 38(2), 209-219

Butterfield, P. S., \& Leclair, S. (1988). Cognitive characteristics of bulimic and drug-abusing women, Addictive Behaviors, 13(2), 131-138.

Cacioppo, J. T., Hawkley, L. C., \& Berntson, G. G. (2003). The anatomy of loneliness, Current Directions in Psychological Science, 12(3), 71-74.

Cooper, A. C., Woo, C. Y., \& Dunkelberg, W. C. (1988). Entrepreneurs' perceived chances for success. Journal of Business Venturing, 3(2), 97-108.

Dunning, D. (2005). Self-insight: Roadblocks and detours on the path to knowing thyself, New York, NY: Psychology Press.

Dunning, D., Heath, C., \& Suls, J. M. (2004). Flawed selfassessment: Implications for health, education, and the workplace, Psychological Science in the Public Interest, 5(3), 69-106.

Duval, S., \& Wicklund, R. A. (1972). A theory of objective selfawareness. San Diego, CA: Academic Press. 
Eisenberger, N. I., Liberman, M. D., \& Williams, K. D. (2003) Does Rejection Hurt? An fMRI Study of Social Exclusion," Science, 302 (October), 290-292.

Fabricius, G., \& Büttgen, M. (2013). The influence of knowledge on overconfidence: Consequences for management and project planning, International Journal of Business and Management, $8(11), 1-12$.

Faver, R. J. (2004). Self-control and compulsive buying, In T. Kasser, \& A. D. Kanner (Eds.), Psychology and consumer culture: The struggle for a good life in a materialistic world (pp. 169-187). Washington: The American Psychological Association.

Gigerenzer, G. (2008). Rationality for mortals: How people cope with uncertainty. New York: Oxford Univ. Press.

Han, W. H. (2020a). Does social exclusion influence consumers' pseudodiagnosticity biases towards distribution brands? Journal of Distribution Science, 18(4), 79-85.

Han, W. H. (2020b). Impulsive buying and social exclusion. Journal of Product Research, 38(3), 53-59.

Han, W. H. (2020c). The study on compulsive buying as selfdefeating behavior: Focused on social exclusion factor," East Asian Journal of Business Economics, 8(2), 57-68.

Han, W. H. (2020d). How consumers' mindfulness moderates impulsive buying tendency. Services Marketing Journal, 13(1), 5-17.

Heatherton, T. F., \& Baumeister, R. F. (1991). Binge Eating as Escape from Self-Awareness, Psychological Bulletin, 110(1), 86-108.

Hoffrage, U. (2004). Overconfidence, In R. F. Pohl (Eds.), Cognitive illusions: A handbook of fallacies and biases in thinking, judgment and memory (pp. 235-254). Hove and New York: Psychology Press.

Kahnemann, D., \& Frederick, S. (2002). Representativeness revisited: Attribute substitution in intuitive judgment, In T. Gilovich \& D. Griffin (Eds.), Heuristics and biases: The psychology of intuitive judgment (pp. 49-81). Cambridge University Press.

Kahneman, D., \& Tversky, A. (1982), Judgment under uncertainty: Heuristics and biases. New York: Cambridge Univ. Press.

Kahneman, D., \& Tversky, A. (1996). On the reality of cognitive illusions, Psychological Review, 103(3), 582-591.

Kim, J. K., \& Yang, H. C. (2019). Effects of heuristic type on purchase intention in mobile social commerce: Focusing on the mediating effect of shopping value, Journal of Distribution Science, 17(10), 73-81.

Kruger, J., \& Burrus, J. (2004). Egocentrism and focalism in unrealistic optimism (and pessimism), Journal of Experimental Social Psychology, 40(3), 332-340.

Lee, J. S., Chun, S., \& Choi, J. (2019). South Korean consumers' experiences and underlying shopping mechanism of Black Friday, Journal of Distribution Science, 17(11), 63-72.

Logg, J. M., Haran, U., \& Moore, D. A. (2018). Is overconfidence a motivated bias? Experimental evidence, Journal of Experimental Psychology: General, 147(10), 1445-1465.

Moore, D. A., \& Small, D. A. (2007). Error and bias in comparative judgment: On being both better and worse than we think we are, Journal of Personality and Social Psychology, 92(6), 972-989.

Smith, E. R., Murphy, J., \& Coats, S. (1999). Attachment to Groups: Theory and Measurement, Journal of Personality and Social Psychology, 77(1), 94-110.

Stanovich, K. E., \& West, R. F. (2000). Individual differences in reasoning: Implications for the rationality debate, Behavioral and Brain Sciences, 23(5), 645-726.

Svenson, O. (1981). Are we all less risky and more skillful fellow drivers? Acta Psychologica, 47(2), 143-148.

Twenge, J. M., Catanese, K. R., \& Baumeister, R. F. (2003). Social Exclusion and the Deconstructed state: Time Perception, Meaninglessness, Lethargy, Lack of Emotion, and Self-awareness, Journal of Personality and Social Psychology, 85(3), $409-423$.

Wan, E. C., Xu, J., \& Ding, Y. (2014). To Be or Not to Be Unique? The Effect of Social Exclusion on Consumer Choice, Journal of Consumer Research, 40(1), 1109-1122.

Zacharakis, A. L., \& Shepherd, D. A. (2001). The nature of information and overconfidence on venture capitalists' decision making. Journal of Business Venturing, 16(4), 311-332.

Zenger, T. R. (1992). Why do employers only reward extreme performance? Examining the relationships among performance, pay, and turnover. Administrative Science Quarterly, 37(2), 198 -219.

Zuckerman, E. W., \& Jost, J. T. (2001). What makes you think you're so popular? Self-evaluation maintenance and the subjective side of the "friendship paradox." Social Psychology Quarterly, 64(3), 207-223. 